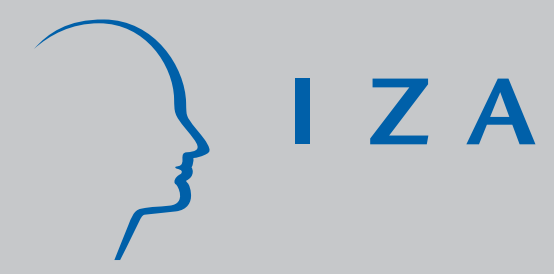

IZA DP No. 3155

Ethnic Sorting in the Netherlands

Aslan Zorlu

J an Latten

November 2007 


\title{
Ethnic Sorting in the Netherlands
}

\author{
Aslan Zorlu \\ AMIDst, AIAS, University of Amsterdam \\ and IZA \\ Jan Latten \\ Statistics Netherlands

\section{Discussion Paper No. 3155 \\ November 2007} \\ IZA \\ P.O. Box 7240 \\ 53072 Bonn \\ Germany \\ Phone: +49-228-3894-0 \\ Fax: +49-228-3894-180 \\ E-mail: iza@iza.org
}

\begin{abstract}
Any opinions expressed here are those of the author(s) and not those of the institute. Research disseminated by IZA may include views on policy, but the institute itself takes no institutional policy positions.
\end{abstract}

The Institute for the Study of Labor (IZA) in Bonn is a local and virtual international research center and a place of communication between science, politics and business. IZA is an independent nonprofit company supported by Deutsche Post World Net. The center is associated with the University of Bonn and offers a stimulating research environment through its research networks, research support, and visitors and doctoral programs. IZA engages in (i) original and internationally competitive research in all fields of labor economics, (ii) development of policy concepts, and (iii) dissemination of research results and concepts to the interested public.

IZA Discussion Papers often represent preliminary work and are circulated to encourage discussion. Citation of such a paper should account for its provisional character. A revised version may be available directly from the author. 
IZA Discussion Paper No. 3155

November 2007

\section{ABSTRACT}

\section{Ethnic Sorting in the Netherlands ${ }^{*}$}

This paper examines the residential mobility behaviour of migrants and natives in the Netherlands using a rich administrative individual data file. The inclination to move and the choice of destination neighbourhood are estimated, correcting for the selection bias of movers. Subsequently, the role of preferences in the mobility behaviour is implicitly derived from regression estimates. The analysis shows that the percentage of natives in the destination neighbourhood is predicted to be about 18 percentage points lower for nonwestern migrants than for natives. About 65 percent of the differential is explained by their observable characteristics; the remaining part can largely be attributed to preferences and discrimination. No indication is found of the spatial assimilation of second-generation nonwestern migrants. On the other hand, the mobility pattern of the second-generation western migrants is similar to that of natives.

JEL Classification: J1, J6, R3

Keywords: migrants, residential segregation

Corresponding author:

Aslan Zorlu

AIAS, Amsterdam Institute for Advanced Labour Studies

University of Amsterdam

Plantage Muidergracht 12

1018 TV Amsterdam

The Netherlands

E-mail: A.Zorlu@uva.nl

\footnotetext{
* This research is supported by the Netherlands Organisation for Scientific Research (NWO), VICI grant no. 453-04-001. The paper is part of a joint project with Statistics Netherlands; we are grateful to the Department of Total Statistics for allowing us the use of the Social-Statistical Database.
} 


\section{$1 \quad$ Introduction}

With the massive influx of non-western immigrants from the 1970s onwards, the Netherlands has turned into an immigration country. In the past few decades, large numbers of immigrants from less-developed non-western countries have changed the demographic and social composition of the population at the national level. The newcomers are concentrated in the economic urban centres in the Western part of the country, mainly in older neighbourhoods where houses are cheaper. This tendency to spatial concentration in the older urban parts in the country was accelerated by an ongoing selective suburbanization of natives. As a result, many neighbourhoods in the four largest Dutch cities of Amsterdam, Rotterdam, The Hague, and Utrecht have become predominantly inhabited by migrants.

Government policies on the national and local levels seek to counteract this tendency. Most policy measures are based on the assumption that the spatial segregation of the poor derives from their individual economic position. If a neighbourhood becomes less popular, those who cannot afford to live in a more expensive neighbourhood stay and are joined by newcomers who are equally impoverished. Eventually, the selective residential mobility leads to more economic segregation. Since non-western migrants have a less favourable economic position, an outcome of more ethnic segregation is selective mobility. Previous research has demonstrated that disparities in income and wealth play an important part in explaining ethnic residential segregation (Bolt and Van Kempen, 2003). Policy makers tend to focus on the housing market to manipulate residential mobility, because the high density of social-rental houses in the large cities is seen as one of the main sources of ethnic residential segregation. Correspondingly, mixing housing stocks is viewed as an effective instrument to create integrated neighbourhoods where various economic classes and, implicitly, different ethnic groups will reside (Musterd et al., 2003). However, little is known about the driving forces in the ongoing process of ethnic spatial segregation on a local level. This study examines ethnic differences in mobility patterns in the Netherlands and aims to assess the role of observed characteristics and unobserved factors such as preferences and discrimination.

In addition to disparities in individual socioeconomic positions, preferences can drive location choice according to the ethnic composition of the neighbourhood. One can argue that the preferences of natives, the dominant group, are more important in initiating the outflow and the transformation of a neighbourhood, because natives are in a relatively advantageous position. They have more opportunities to realize their preferences to live in a neighbourhood with a desired ethnic composition. Whatever the reasons from which they may be derived, native segregatory taste or intolerance does not need to be very pronounced. Schelling (1971) suggests in his segregation model that the individual behaviour of the dominant group, even if based on minor differences in preferences, can lead to segregation in urban areas, even in the absence of other segregating forces.

Preferences regarding the ethnic makeup of the neighbourhood are difficult to identify in the absence of qualitative information on stated preferences. The housing demand survey contains some information, but it is unsatisfactory. Such data are not available in the Netherlands. Instead, we have used a rich individual administrative data file from 2002 and 2003 (SSD) housed by Statistics Netherlands. This unique database allows ethnic differences to be considered with respect to many individual demographic and socioeconomic characteristics, as well as relevant 
neighbourhood characteristics and housing market restrictions. Additionally, the attachment to residence location is approximated by the presence of parents in the same municipality, bearing in mind recent evidence of the relatively great adverse effect of family ties on mobility behaviour among blacks and low-income groups (Spilimbergo and Ubeda, 2004; Dawkins, 2006). The data allow individual geographical mobility to be tracked, but do not include direct information on stated preferences. Therefore, to uncover the role of preferences and discrimination in ethnic segregation process, an implicit strategy has been applied: the Oaxaca-Blinder decomposition technique. This identifies the contribution of observed relevant factors in data to the mobility behaviour. The remaining unexplained part of mobility behaviour may be attributed to preferences and discrimination, which we refer to here as preferences. The role of more explicit discrimination in the Dutch housing market is likely to be more limited and more embedded in preferences than in the United States. However, the unexplained part could also be the result of some other factors that are not in our data. Nevertheless, this study has the potential to distinguish the preference component of ethnic residential sorting in the Netherlands, because most relevant factors are taken adequately into account.

The paper is organized as follows: the next section gives a brief history of immigration to the Netherlands and ethnic spatial concentration. Section 3 consists of a description of the data file used. In Section 4, we discuss the analytical framework to estimate the geographical mobility patterns by ethnic background. In Section 4, the mobility differentials are decomposed into explained and unexplained components. Section 5 concludes.

\section{Trends in spatial concentration}

The recruitment of guest workers from Mediterranean countries, Turkey and Morocco in particular, initiated a continuous growth of the share of non-western migrants in the Dutch population. Many of the guest workers did not return home and formed the basis of immigrant communities that grew rapidly through family reunification in the 1970s and 1980s and family formation in more recent years. In the mid-1970s, immigration flows from the former Netherlands colonies of Surinam and the Antilles gave an additional impetus to the growing share of immigrant population. In addition, immigration from developed countries has comprised almost half the immigration flows and has followed business cycles. During the 1990s, asylum seekers dominated immigration flows. Between the early 1970s and 2007, the new non-western population has grown tenfold from 160,000 to 1.7 million, including the second generation, while the number of western migrants has reached 1.4 million.

The Netherlands population has always been concentrated in the western part of the country where economic activities are concentrated, and today this tendency is even more marked for the newcomers. At the regional level, the newcomers are concentrated in the cheaper areas in the urban zones, mainly in the older neighbourhoods with cheaper houses. In contrast with other migrants, the Surinamese and Antillean population have also settled in some newly-built housing stock. Asylum seekers in the 1990s spread out on arrival, but later also tended to move to the cities (Zorlu and Mulder, forthcoming).

The regional and urban concentration tendencies on arrival in the Netherlands have coincided with the already established residential suburbanization process of natives, which accelerated in the 1960s. Since the 1970s, this suburbanization has resulted in a sharp decline of the -at that time- mainly native urban population. At the same time, a mainly non-western foreign-born 
population settled in these cities and partly compensated for the native Dutch residential outflow, so that the total number of inhabitants of Amsterdam, Rotterdam, The Hague, and Utrecht has been stable since the mid-1980s. This quantitative stability in population size, however, hides the ongoing social demographic dynamics in population composition, especially regarding ethnicity. This ethnic selective residential mobility has correlated with the socioeconomic status of movers (Musterd et al., 2007). Next to the ethnicity-specific migration patterns, natural growth figures differentiate similarly according to ethnic background. The native city population shows a clear excess of deaths over births, while the natural increase of the non-western foreign population stimulates the overall natural increase in the large cities. The combination of migration and natural growth trends explains the very fast changes in ethnic composition of the four largest Dutch cities (Bontje and Latten, 2005).

Among migrants, residential segregation is stronger for those of non-western origin. In 2004, 10 percent of the Dutch population was non-western, but in the four largest cities their share was one third. Within these cities their concentration is even stronger. In some neighbourhoods in The Hague, Amsterdam or Rotterdam, the share of non-western foreigners has reached levels above 70 percent and even 80 percent, in contrast with the national share of 10 percent. The structure of the housing market is probably an important factor in the Netherlands. Local housing markets in large cities are dominated by social rental housing and an extension of the housing stock is subject to physical limitations. The presence of a social housing sector with a non-competitive rental policy below market prices together with tight regulations generates a formidable rationing regime. Choices within the same city are limited for those who want to improve their housing quality by moving to a larger and more comfortable home. The suburbs are a logical option for short-distance mobility induced by economic and life cycle factors. In this study, housing market conditions generating this type of mobility have been carefully controlled for.

While the suburbanisation trend of natives continues, the non-western population is also suburbanising. At first glance one can welcome this tendency as proof of the social mobility of non-western inhabitants who participate in a general pattern like the suburbanization process, and respond in a similar manner to shortages in urban housing stock. However, one can also see that the direction of suburbanisation for ethnic groups is not a random process. It is rather selective. Migrant movers from large cities choose municipalities where their co-ethnics are residing, while the native outflow heads for other places. This pattern may be an indication not only of socioeconomic upward mobility, but also of ethnic preferences.

\section{Previous research}

Previous research has provided evidence that differences in preferences have certainly been influential in neighbourhood racial and ethnic transition, even when account is taken of other segregating forces such as individual and family-level variables and non-ethnic neighbourhood characteristics. The preferences of the dominant group have two components: moving out; not moving into an area where the share of ethnic minority groups is high and growing. Earlier studies considered only the outflow of whites, regarded as white flight. More recently, the role of whites has been expressed as white avoidance, which captures both outflow from, and not moving into, ethnically mixed areas (Quillian, 2002; Crowder, 2000; Clark, 1992).

Recent studies argue that the concentration of blacks and low-income families is persistent owing to the low inter-neighbourhood mobility of these groups. Spilimbergo and Ubeda, 2004 
demonstrate the importance in the decision to migrate of family attachment, but it is much more important for Blacks than for Whites, despite their many characteristics associated with high geographical mobility such as a low rate of marriage and home ownership and high unemployment. Dawkins, 2006 shows that the inter-neighbourhood mobility of families with children is negatively affected by local kinship ties and the social networks of children. The effect of local social ties is particularly strong for low-income families. In this study we consider an individual's attachment to the residence location, which is approximated by the presence of parents in the same municipality.

Studies using surveys of stated preferences suggest that the willingness of whites to live in a multiethnic area decreases as the share of Blacks, Hispanics, and Asians in a neighbourhood increases and the tolerance of whites has increased in the course of time. These studies also suggest that the tolerance is higher for the ethnic makeup of origin location than for a desired ethnic composition of the destination neighbourhood (Farley et al., 1978, 1994; Galster, 1990; Clark, 1992; Krysan, 2002). The observed trend in ethnic and racial segregation confirms the indications of survey research (Crowder, 2000; Cutler et al., 1999). Although some members of the dominant group seem to have higher degrees of tolerance, individual behaviour culminates in aggregate results that are associated with higher observed level of ethnic residential segregation than expected. Schelling, 1971 linked aggregate population processes to individual behaviour in his neighbourhood tipping model, which predicts that unorganized individual behaviour based on slight differences in preferences can generate a perpetual process of white flight, culminating in the loss of even more tolerant whites. Drawing on data on either stated preferences or actual patterns, American researchers have established that many urban areas have experienced a drastic transition, given the extent of housing facilities, which suggests the existence of a critical point of racial composition - neighbourhood tipping - above which white avoidance perpetuates ethnic and racial segregation. This evidence is consistent to life course developments captured by a large number of relevant variables that may influence spatial mobility (Crowder et al., 2006; Cutler et al.,1999; Galster,1990)

Data employed in segregation research usually include either stated preferences or actual mobility behaviour, but seldom both, because actual mobility behaviour follows the preference statement with a time lag that in survey studies is hard to capture. Survey studies based on expressed preferences and attitudes provide some indications about the possible effect of an ethnic/racial component of individual mobility, but are unable to identify their influences on actual mobility behaviour. On the other hand, data on actual mobility patterns without preference assessment cannot fully measure the role of preferences. These are likely to be correlated with many individual and family-level factors as well as non-ethnic neighbourhood characteristics. Perhaps this is the reason why researchers have not been able to provide direct evidence of the impact of preferences. In this study, preferences are derived from mobility behaviour. Differences in the ethnic composition of destination neighbourhood between natives and migrants are decomposed into explained and unexplained components, as formally shown in section 4 .

In Europe, research on segregation is scarce, probably because of the relatively low levels of ethnic concentration and small number of segregated areas in urban areas (Musterd, 2005). Dutch data suggest that neighbourhoods that already had higher concentrations of ethnic population showed faster transformation to segregation than other neighbourhoods (Latten, Nicolaas and Wittebrood, 2005). However, solid evidence of the role of preferences in the segregation 
tendency is lacking in European research. This study contributes to our understanding of the dynamics of segregation.

\section{Data}

We have used a rich individual administrative databank from 2002 and 2003, the Social Statistical Database (SSD) housed by Statistics Netherlands. The data cover the entire population of the Netherlands. The occurrence of mobility between neighbourhoods is identified by comparing the residence neighbourhoods on the third Friday of September 2002 and 2003. The availability of data on two points in time enables us to observe the origin and destination neighbourhoods and the changes in individual and household statutes as well as neighbourhood conditions, although the last will probably be very small. Since the data cover the entire population and national geographical area, we have been able to construct aggregate variables on the neighbourhood level, which is the smallest available spatial area in the data, with an average of about 1700 residents.

After estimating the neighbourhood transition matrix displayed in table 2, we took a random sample of 1 percent from the entire population of around 16.4 million to be able to perform more sophisticated regression analyses that would otherwise be impossible to conduct with the technical capacity available. Furthermore, we restricted the sample to people aged 18 to 64 years who are potentially decision makers in the household, since the head of household is not identified in the data.

For the analysis, three major groups are distinguished: natives, non-western migrants, and western migrants. The last category contains migrants from developed countries. The nonwestern category consists of the migrants from developing countries. It is dominated by four large groups: Turks, Surinamese, Moroccans, and Antilleans. Table 1 gives the descriptive statistics for a large number of individual and neighbourhood-level variables for the three main groups. In addition to the main demographic and household characteristics, the transition in household structure is also given by two dummy variables indicating the transition between single and married status. The socioeconomic position is measured by dummy variables defined on the basis of income source as employed, unemployed, student, receiver of another benefit, and inactive, which is the reference category. Additionally, separate dummies have been constructed to control for the levels of earned income defined as the quartiles of the distribution. The neighbourhood characteristics are approximated by a set of variables indicating the mean income, the unemployment rate, the share of owner-occupied houses, the mean value of houses, and the share of non-western migrants. To approximate the degree of neighbourhood attachment, three control variables are used to indicate the presence of parents in the municipality (both parents; one parent; no parents in the municipality) with parents not alive as the reference. We have considered the municipality level rather than the neighbourhood, because municipalities and distances are relatively small and transportation in the Netherlands is easy. Unfortunately, this rich data file does not include information on education, which is a very important variable in this kind of research.

It immediately becomes apparent that there are substantial differences between the characteristics of natives and non-western migrants. Western migrants are similar to natives; more than half of them were born in the Netherlands, while only 15 percent of non-western migrants are second generation. Non-western migrants are relatively young and are less likely to be employed or 
homeowners. Their household size is large and they are less likely to reside apart from their parents. Their concentration is substantially high in the three largest cities of Amsterdam, Rotterdam, and The Hague. They live more often in neighbourhoods where the value of houses is relatively low and the unemployment rate is high.

Table 1. Mean values of variables used, population between 18 and 64 years old in 2002

\begin{tabular}{|c|c|c|c|}
\hline Variable & Native & Non-western & Western \\
\hline Age & 41.05 & 35.25 & 40.57 \\
\hline Woman & 0.49 & 0.48 & 0.51 \\
\hline Second Generation & na & 0.15 & 0.55 \\
\hline Homeowner & 0.65 & 0.23 & 0.50 \\
\hline The value of home in $1000 \mathrm{~s}$ & 154.02 & 100.43 & 147.28 \\
\hline Married & 0.57 & 0.48 & 0.49 \\
\hline Number of children in household & 1.02 & 1.26 & 0.83 \\
\hline Number of persons in household & 2.85 & 3.02 & 2.60 \\
\hline From single to marry & 0.02 & 0.01 & 0.02 \\
\hline From couple to single & 0.01 & 0.01 & 0.01 \\
\hline Employed & 0.70 & 0.47 & 0.60 \\
\hline Unemployed & 0.03 & 0.15 & 0.05 \\
\hline Receiver of a benefit & 0.11 & 0.09 & 0.11 \\
\hline Student & 0.05 & 0.07 & 0.04 \\
\hline Labour income Q1-Q2 & 0.18 & 0.22 & 0.19 \\
\hline Labour income Q2-Q3 & 0.25 & 0.20 & 0.21 \\
\hline Labour income $>\mathrm{Q} 3$ & 0.41 & 0.35 & 0.44 \\
\hline Mean value of homes in neighbourhood (in 1000s) & 154.22 & 114.65 & 148.99 \\
\hline Mean annual labour income in neighbourhood & 23669 & 21395 & 23909 \\
\hline$\%$ owner occupied homes in neighbourhood & 58.82 & 39.21 & 51.72 \\
\hline Unemployment rate in neighbourhood & 3.12 & 7.92 & 4.25 \\
\hline$\%$ non-western in the origin neighbourhood & 7.92 & 28.27 & 11.71 \\
\hline Both parents in the same municipality & 0.26 & 0.18 & 0.14 \\
\hline One parent in the same municipality & 0.10 & 0.07 & 0.08 \\
\hline No parent in the same municipality & 0.36 & 0.11 & 0.24 \\
\hline Amsterdam & 0.03 & 0.15 & 0.08 \\
\hline Rotterdam & 0.03 & 0.13 & 0.04 \\
\hline The Hague & 0.02 & 0.08 & 0.04 \\
\hline Probability of moving & 0.088 & 0.141 & 0.096 \\
\hline Share of natives in destination neigh. & 80.463 & 61.833 & 74.220 \\
\hline $\mathrm{N}$ & 84706 & 10363 & 10276 \\
\hline
\end{tabular}

\subsection{Mobility pattern}

The differences between the residential mobility patterns of natives and immigrant groups can be shown using some categories for the degrees of concentration of non-western migrants. We define seven neighbourhood types using 10 percent intervals up to 60 percent and one interval for the higher degrees. Since we are interested in examining a single mobility (2002 to 2003), the inter-(and intra-)neighbourhood mobility among these seven categories can be captured by a $\mathrm{K} \mathrm{x}$ $\mathrm{K}$ transition matrix, $\mathrm{A}$ 


$$
A=\left(\begin{array}{ccccc}
a_{11} & \cdot & \cdot & \cdot & a_{17} \\
\cdot & \cdot & \cdot & \cdot & \cdot \\
\cdot & \cdot & \cdot & \cdot & \cdot \\
\cdot & \cdot & \cdot & \cdot & \cdot \\
a_{71} & \cdot & \cdot & \cdot & a_{77}
\end{array}\right)
$$

where the $\mathrm{ij}^{\text {th }}$ element $a_{i j}$ represents the probability of moving from neighbourhood $i$ in 2002 to neighbourhood $j$ in 2003. The $\mathrm{i}^{\text {th }}$ row contains the probabilities of moving from neighbourhood $i$ in 2002 to each of $K$ neighbourhood types in 2003. Thus, the elements of each row sum to 1 . We estimate the elements of A from observed transitions using the estimator.

$$
a_{i j}=\frac{M_{i j 2003}}{N_{i, 2002}}
$$

where $M_{i j 2003}$ is the number of inhabitants in neighbourhood $j$ in 2003 who were in neighbourhood $i$ in 2002, and $N_{i, 2002}$ is the number of inhabitants in neighbourhood $i$ in 2002. We have estimated transition probabilities separately for natives, non-western, and western migrants.

Table 2 presents the estimates of a matrix of transition probabilities. The last two columns have been added to reveal the distribution of the population and the propensity to move over the neighbourhood type. The second column from the right shows that the propensity to move among natives increases monotonically with the share of non-western migrants in the neighbourhood. The propensity to move is slightly lower when the share of non-western migrants is less than 21 percent. A similar pattern holds for western migrants. On the other hand, for non-western migrants the propensity to move is almost constant at around 14 percent across the neighbour types.

Ethnic sorting becomes more visible when we look at the destination-neighbourhood type of movers. The entries in the rows of the table show the redistribution of individuals living in neighbourhood $i$ in 2002 over the neighbourhood types one year later. The diagonal of the matrixes shows the preservation in the same neighbourhood types for natives and immigrant groups. The distribution above the diagonal shows the dispersion of population towards locations with more migrants, while the distribution below the diagonal shows dispersion in the opposite direction. Note that also not movers are included in the calculations, in addition to movers, whereby the change in the neighbourhood ethnic composition looks like small. It is immediately apparent that natives are mainly diffused over the neighbourhoods with a lower percentage of non-western migrants (that is, there is more dispersion below the diagonal), while the distribution of migrants - especially non-western migrants - is more prominent above the diagonal.

Natives residing in the neighbourhoods where less than 10 percent of the population is non-native are less inclined to move. If they do, their destination is more likely to be a low (immigrant) concentration area. When they reside in neighbourhoods with more non-western neighbours, their destination is often a less concentrated neighbourhood. 
Table 2. Transition probabilities and the distribution of movers over neighbourhood types referring to the share of non-western migrants in the neighbourhood

\begin{tabular}{|c|c|c|c|c|c|c|c|c|c|c|}
\hline \multirow{2}{*}{\multicolumn{2}{|c|}{$\begin{array}{l}\% \text { non-western in the } \\
\text { origin neighbourhood }\end{array}$}} & \multicolumn{7}{|c|}{$\%$ non-western in the destination neighbourhood (2003) } & \multirow[b]{2}{*}{$\%$ Movers } & \multirow[b]{2}{*}{ Total } \\
\hline & & $0-1 \%$ & $11-20 \%$ & $21-30 \%$ & $31-40 \%$ & $41-50 \%$ & $51-60 \%$ & $61-100 \%$ & & \\
\hline \multirow[t]{8}{*}{ Natives } & $0-10 \%$ & 0.971 & 0.023 & 0.003 & 0.001 & 0.001 & 0.000 & 0.000 & 7.0 & 10254504 \\
\hline & $11-20 \%$ & 0.068 & 0.854 & 0.069 & 0.004 & 0.002 & 0.001 & 0.001 & 9.3 & 1701870 \\
\hline & $21-30 \%$ & 0.051 & 0.040 & 0.860 & 0.043 & 0.004 & 0.001 & 0.001 & 10.7 & 590195 \\
\hline & $31-40 \%$ & 0.044 & 0.026 & 0.039 & 0.787 & 0.099 & 0.003 & 0.002 & 11.4 & 289265 \\
\hline & $41-50 \%$ & 0.041 & 0.030 & 0.018 & 0.040 & 0.796 & 0.071 & 0.004 & 11.8 & 124816 \\
\hline & $51-60 \%$ & 0.039 & 0.029 & 0.020 & 0.014 & 0.077 & 0.814 & 0.007 & 13.2 & 64674 \\
\hline & $61-100 \%$ & 0.034 & 0.028 & 0.022 & 0.016 & 0.033 & 0.018 & 0.850 & 14.2 & 61412 \\
\hline & Total & & & & & & & & 7.7 & 13086736 \\
\hline \multirow[t]{8}{*}{ Non-western } & $0-10 \%$ & 0.894 & 0.069 & 0.016 & 0.008 & 0.005 & 0.003 & 0.004 & 13.5 & 432735 \\
\hline & $11-20 \%$ & 0.045 & 0.819 & 0.106 & 0.013 & 0.008 & 0.004 & 0.005 & 13.1 & 327924 \\
\hline & $21-30 \%$ & 0.028 & 0.039 & 0.844 & 0.064 & 0.010 & 0.007 & 0.008 & 14.0 & 218778 \\
\hline & $31-40 \%$ & 0.019 & 0.024 & 0.039 & 0.770 & 0.124 & 0.009 & 0.015 & 14.3 & 183206 \\
\hline & $41-50 \%$ & 0.018 & 0.022 & 0.019 & 0.043 & 0.783 & 0.093 & 0.022 & 14.0 & 123447 \\
\hline & $51-60 \%$ & 0.013 & 0.022 & 0.022 & 0.019 & 0.083 & 0.824 & 0.018 & 14.9 & 93688 \\
\hline & $61-100 \%$ & 0.010 & 0.015 & 0.017 & 0.019 & 0.033 & 0.016 & 0.890 & 15.7 & 192098 \\
\hline & Total & & & & & & & & 14.0 & 1571876 \\
\hline \multirow[t]{8}{*}{ Western } & $0-10 \%$ & 0.954 & 0.035 & 0.006 & 0.002 & 0.001 & 0.001 & 0.001 & 8.1 & 936859 \\
\hline & $11-20 \%$ & 0.059 & 0.857 & 0.072 & 0.006 & 0.004 & 0.002 & 0.001 & 9.8 & 252401 \\
\hline & $21-30 \%$ & 0.045 & 0.039 & 0.859 & 0.045 & 0.005 & 0.003 & 0.002 & 11.2 & 101659 \\
\hline & $31-40 \%$ & 0.036 & $0.028^{\circ}$ & 0.036 & 0.796 & 0.096 & 0.004 & 0.004 & 11.6 & 55507 \\
\hline & $41-50 \%$ & 0.038 & 0.030 & $0.019^{7}$ & 0.042 & 0.785 & 0.077 & 0.008 & 12.3 & 28166 \\
\hline & $51-60 \%$ & 0.036 & 0.034 & 0.031 & 0.018 & 0.098 & 0.775 & 0.009 & 14.9 & 17116 \\
\hline & $61-100 \%$ & 0.028 & 0.026 & 0.020 & 0.016 & 0.034 & 0.016 & 0.860 & 14.4 & 19553 \\
\hline & Total & & & & & & & & 9.0 & 1411261 \\
\hline
\end{tabular}

Note this table is based on the entire population of the Netherlands

\section{Analytical strategy}

We first consider the subset of movers alone and regress the native concentration onto the mover's destination, $y_{i}$ on a vector of some individual demographic and economic variables, $W_{i}$ and a vector of the immigrant groups distinguished, $I_{i}$.

$$
y_{i}=W_{i} \delta+I_{i} \eta+\mu_{i}
$$

The parameters of this model are estimated by an ordinary least square (OLS) estimator neglecting the possible selectivity of movers. To assess the impact of variable groups, four models were estimated, starting with a simple model with the most exogenous variables. Subsequently, the model was extended with variables reflecting the demographic, household, and socioeconomic position of individuals, the neighbourhood ethnic composition, and the three largest cities. Standard errors have been adjusted at the municipality level, since neighbourhoods are nested in municipalities. The estimates are presented in table 3 . All variables refer to the first year prior to moving (2002), except those indicating the change in marital status (from single to married and from couple to single). The analysis shows that the native concentration in the destination neighbourhood is 12 to 21 points lower for non-western immigrant groups (that is, the Turks, Moroccans, Surinamese, Antilleans and other non-western groups) after controlling for all background variables, except the percentage of non-western migrants in the origin neighbourhood and the three largest cities. Including this last variable has a substantial influence on the immigrant groups' coefficients; they are almost 50 percent lower. This suggests that almost half the segregatory behaviour of non-western migrants can be explained by the fact that 
they were living in segregated areas. An alternative explanation is that migrants, especially nonwestern migrants living in segregated areas, are less likely to move to native neighbourhoods.

Table 3. Regression estimates of the destination-neighbourhood type of movers (Dependent variable is percentage of natives in the destination neighbourhood)

\begin{tabular}{|c|c|c|c|c|}
\hline Variable & Model I & Model II & Model III & Model IV \\
\hline Woman & 0.787 * & 0.590 * & $0.920 * *$ & $0.967^{* *}$ \\
\hline Age $18-25$ & $-3.617 * \star \star$ & $-2.360 * \star \star$ & $-1.769 *$ & $-2.115 * \star$ \\
\hline Age $26-35$ & -1.165 & -0.358 & -1.118 & -0.874 \\
\hline Age $36-45$ & -0.575 & -0.779 & -1.493 & -1.000 \\
\hline Age $46-55$ & -0.558 & -0.681 & -1.247 & -1.355 \\
\hline Moroccan & $-22.172 * \star \star$ & $-21.060 * * *$ & -20.314 *** & $-11.390 * * \star$ \\
\hline Turkish & $-16.710 * \star \star$ & -16.435 *** & -16.014 *** & $-8.809 * * *$ \\
\hline Surinamese & $-24.410 * \star \star$ & $-22.705^{\star \star \star}$ & $-22.282^{\star \star \star}$ & $-11.073 * \star *$ \\
\hline Antillean & $-21.938 * \star *$ & -19.344 *** & $-18.307^{* \star \star}$ & $-11.501 * \star *$ \\
\hline Other Non-western & $-16.614^{\star \star \star}$ & $-15.412^{\star \star \star}$ & -14.661 *** & $-9.589 * \star \star$ \\
\hline Western & $-9.572 * \star \star$ & $-8.684 * \star \star$ & -8.321 *** & $-6.136 * \star \star$ \\
\hline Second generation & $5.540 * \star \star$ & 5.244 *** & $5.062 * \star \star$ & $3.427^{\star \star \star *}$ \\
\hline Homeowner & & $3.954 * \star *$ & 3.853 *** & $1.111^{* \star *}$ \\
\hline Married & & $2.909 * \star \star$ & 2.576 *** & $2.335^{* * *}$ \\
\hline Number of children in household & & $-0.811 *$ & $-0.641 *$ & $-0.679 *$ \\
\hline Number of persons in household & & $1.183 * \star \star$ & $1.084 * * *$ & $0.609 * *$ \\
\hline From single to married & & $4.303 * \star \star$ & $3.493 * \star *$ & $3.242 * \star *$ \\
\hline From couple to single & & $-3.116 * \star \star$ & $-2.937 * \star$ & $-3.250 * * *$ \\
\hline Employed & & & $2.098 * \star$ & $2.418 * \star *$ \\
\hline Unemployed & & & $-2.246 *$ & 0.030 \\
\hline Receiver of a benefit & & & 1.344 & 1.039 \\
\hline Student & & & $-2.791 *$ & $-2.307 *$ \\
\hline Labour income Q1-Q2 & & & 0.247 & 0.468 \\
\hline Labour income Q2-Q3 & & & 0.504 & 0.615 \\
\hline Labour income $>Q 3$ & & & 0.594 & 0.893 \\
\hline \%non-western in the origin neighbourh. & & & & $-0.309 * \star *$ \\
\hline Amsterdam & & & & $-11.478 *$ \\
\hline Rotterdam & & & & $-8.402 *$ \\
\hline The Hague & & & & $-9.781^{\star \star \star}$ \\
\hline Constant & $81.822^{\star \star \star}$ & 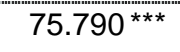 & 74.574 *** & $81.090^{\star \star \star}$ \\
\hline R-sq & 0.18 & 0.21 & 0.22 & 0.38 \\
\hline $\mathrm{N}$ & 9799 & 9549 & 9549 & 9511 \\
\hline
\end{tabular}

$* \mathrm{p}<.05 ; * * \mathrm{p}<.01 ; * * * \mathrm{p}<.001$.

Standard errors are clustered on the municipality level

However, OLS estimates will not provide consistent and asymptotically efficient parameter estimates if the decision to move is correlated with the choice of destination-neighbourhood type. Intuitively and theoretically, there are two reasons why these two decisions could be interrelated. First, individuals may decide to move when they intend to sort themselves by ethnic background. Second, more fundamentally, an individual facing a choice set will potentially make a nonrandom selection. Again, this suggests the selectivity of movers. The decision to move and the choice of destination-neighbourhood type are both choices. Preferences bounded by household income and housing market conditions are likely to play an important part in generating selective 
mobility. This line of argumentation has led us to estimate a selection model which allows these decisions to be correlated (Heckman, 1979; Wooldridge, 2002).

\subsection{Selection Model}

The patterns of residential mobility of both natives and ethnic minorities reflect the process of ethnic residential segregation. In this process, the movers' choice of destination-neighbourhood type is central to this study. Since the decision to move is also a choice given all relevant restrictions on the mobility, movers are likely to be inclined to choose a certain neighbourhood type. The selectivity of movers will differ strongly across ethnic groups if an ethnic sorting process is in operation. We consider the selectivity of movers in examining the choice of the destination-neighbourhood type in terms of the percentage of natives.

The location choice of an individual household follows a two-equation selection model. The destination of the move is given by a linear model (the outcome equation), while the inclination to move is determined by a probit model (selection equation).

Let the choice of destination location and the decision to move for individual $i$ be expressed by the following functions:

The outcome equation: $P_{i}=X_{i} \beta+\varepsilon_{i}$

The selection equation: $M_{i}^{*}=Z_{i} \gamma+u_{i}$

where $P_{i}$ is the percentage of natives in the destination neighbourhood, $X_{i}$ is a vector of individual characteristics determining the location choice and the immigrant position, $M_{i}^{*}$ is a latent variable indicating the propensity to move that is observed as a binary variable taking the value 1 if moved and 0 if not moved, $Z_{i}$ is a vector of determinants of moving and the immigrant position, $\beta$ and $\gamma$ are the associated parameter vectors to be estimated, and $\varepsilon_{i}$ and $u_{i}$ are error terms that follow a bivariate normal distribution $\left(0,0, \sigma_{\varepsilon}, \sigma_{u}, \rho\right)$.

The probability of moving is represented by a probit model

$$
\operatorname{Pr}\left(M_{i}^{*} \succ 0\right)=\operatorname{Pr}\left(u_{i} \succ-Z_{i} \gamma\right)=\Phi\left(Z_{i} \gamma\right)
$$

where $\Phi($.$) is the standard normal cumulative distribution function. The destination location type$ is only observed for those for whom $M_{i}^{*} \succ 0$, so that the expected neighbourhood type of movers is determined as:

$$
\begin{aligned}
E\left(P_{i} \mid M_{i}^{*} \succ 0\right) & =X_{i} \beta+E\left(\varepsilon_{i} \mid u_{i} \succ-Z_{i} \gamma_{i}\right) \\
& =X_{i} \beta+\theta \lambda_{i}
\end{aligned}
$$

where $\theta=\rho \sigma_{i}, \lambda_{i}=\phi\left(Z_{i} \gamma\right) / \Phi\left(Z_{i} \gamma\right)$ and $\phi($.$) is the standard normal density function. The$ location choice function in the presence of sample selectivity to be estimated is expressed as 


$$
E\left(P_{i} \mid M_{i}^{*} \succ 0\right)=X_{i} \beta+\theta \lambda_{i}+v_{i}
$$

where $v_{i}$ is the error term. The parameters of (1) and (2) can be estimated by the maximum likelihood (MLE) method allowing the correlation of the error terms ${ }^{1}$ (Wooldridge, 2002). The selection model can be successfully estimated, because we have a number of explanatory variables potentially affecting the inclination to move, but not necessarily the destinationneighbourhood type (Sartori, 2003) (see table 4). These variables are the neighbour characteristics measuring the economic and housing market conditions in the neighbourhood such as the mean value of houses, income level, the share of owner-occupied homes, together with the presence of parent(s) to approximate the local attachment. This large number of variables is certainly a good basis to estimate the proposed selection models, compared to previous applications of selection models, although not all of these variables are supposed to be exogenous to the share of migrants in the destination neighborhoods.

The sign of the selection coefficient is expected to be positive if those who are more likely to choose native neighbourhoods have a higher probability of moving. It will be negative when movers to immigrant neighbourhoods are more likely to move. For the pooled sample, the sign of the selection coefficient is hard to predict, because natives and migrants may have different motives for moving and different preferences for the destination-neighbourhood type.

\subsection{Empirical Results}

First, we estimated the parameters of the outcome and selection models including a various set of variables using the pooled sample. Table 4 displays the estimates of the outcome equation and corresponding selection equation, since both models are important. The selection equation is, in fact, a probit model estimating the probability of moving. The first model includes the individual characteristics in the outcome equation that are strictly exogenous and, additionally, some neighbourhood characteristics in the selection equation to ensure model identification. The following models utilise variables for household situation, socioeconomic position, the concentration of non-western people in origin neighbourhoods, and controls for the three largest cities. In this way, the influence of variable groups can be demonstrated. The selection correction term, lambda, is significantly positive in the models I-IV, which suggests a positive selection by movers. Those who tend to move to neighbourhoods with a higher share of natives are more likely to move. Note that this positive selection does not necessarily hold for all groups. When the same model is estimated separately for natives and immigrant groups, the sign of the selection coefficient is positive for natives and western migrants, but statistically not significant for nonwestern migrants, as discussed in the next section (see table A1 in appendix).

Concentrating first on the estimates of the outcome equation, it is immediately apparent that nonwestern migrants, especially Surinamese and Moroccans are less likely to move to neighbourhoods with a higher share of native population than natives, the reference group. Model

\footnotetext{
${ }^{1}$ Nawata and Nagase (1996) suggests that the MLE is asymptotically much more efficient than Heckman's two step estimator, especially when there is a high degree of multicollinearity between the hazard ratio and explanatory variables. We have not encountered the convergence problem often mentioned in the literature as a disadvantage of the MLE method.
} 
I indicates that the percentage of natives in the destination neighbourhood of Surinamese and Moroccans is 23.29 and 22.77 points lower than that in the destination neighbourhood of native movers when only age and gender controls are used. After controlling for the concentration of non-western migrants in the origin locations, their estimates decline substantially, but remain significantly high at about 10.4 and 11.8, as shown by model IV. Those who lived in ethnicallysegregated neighbourhoods are more likely to move to neighbourhoods with a lower share of natives. This last model indicates a comparable mobility pattern for Turkish and other nonwestern migrants. The native-immigrant difference in the native concentration in destination neighbourhoods is the smallest for western migrants by almost 6 points. On the other hand, the second generation and those who married are more likely to move neighbourhoods with a higher share of natives. This also holds for employed people. The effect of gender and age on the location choice seems to be negligible.

The estimates of the selection equation give the probability of moving. After controlling for observed individual and neighbourhood characteristics, only other non-western migrants have a higher probability of moving. No significant difference was found between natives and other immigrant groups. The higher mobility among non-western migrants is possibly the result of their relatively short stay in the Netherlands. The category of non-western migrants contains a substantial share of asylum migrants and other recent migrants (Zorlu and Mulder, (forthcoming)). Higher observed mobility among other ethnic minority groups is ascribable to their young age structure and household status in comparison with natives. In line with the literature, larger households with a higher degree of local attachment and homeowners are less likely to move, while a change in marital status is strongly associated with mobility. So, the presence of (a) parent(s) in the same municipality has a significant negative effect on the probability of moving. Individuals who live in a better home in the neighbourhood, given a higher value of their own home, are less likely to move. Notably, the mobility behaviour seems to be negatively influenced by the concentration of all non-western immigrant groups in the origin neighbourhood.

Table 4. Estimates of the choice of destination neighbourhood with correction for selection

\begin{tabular}{|c|c|c|c|c|}
\hline & Model I & Model II & Model III & Model IV \\
\hline \multicolumn{5}{|c|}{ Outcome equation (dependent variable is percentage of natives in the destination neighbourhood) } \\
\hline Age 18-25 & 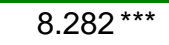 & $8.319 * \star \star$ & 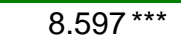 & $2.620 *$ \\
\hline Age $26-35$ & $7.374 * \star *$ & $7.173 * \star \star$ & $6.185^{* * *}$ & 2.461 * \\
\hline Age $36-45$ & $3.289 * *$ & $2.806 *$ & 1.918 & 0.475 \\
\hline Age 46-55 & 0.996 & 0.654 & 0.007 & -0.698 \\
\hline Woman & 0.627 & 0.509 & 0.934 * & 1.017 ** \\
\hline Moroccan & $-22.773^{\star \star \star}$ & $-21.563^{\star \star \star}$ & $-20.742^{\star \star \star}$ & -11.874 *** \\
\hline Turkish & $-17.542^{\star \star \star}$ & $-16.795 * \star \star$ & $-16.234^{\star \star \star}$ & $-8.742^{\star \star \star}$ \\
\hline Surinamese & $-23.287^{\star \star \star}$ & $-21.992^{\star \star \star}$ & $-21.486 * \star \star$ & $-10.401 * \star *$ \\
\hline Antillean & $-19.543 * \star \star$ & $-17.984 * \star \star$ & -16.994 *** & $-10.751 * \star \star$ \\
\hline Other Non-western & $-14.714^{\star \star \star}$ & $-13.385^{\star \star \star}$ & 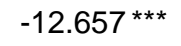 & -8.426 *** \\
\hline Western & $-8.923^{\star \star \star}$ & $-8.087^{\star \star \star}$ & $-7.717^{\star \star \star \star}$ & $-5.873 * \star \star *$ \\
\hline Second generation & $5.243 * \star \star$ & $4.817^{\star \star \star}$ & 4.580 *** & $3.247 * * *$ \\
\hline Homeowner & & $2.717^{*}$ & 2.536 * & 0.427 \\
\hline Married & & -0.097 & -0.406 & 0.835 \\
\hline Number of children in household & & $-1.295^{\star \star \star}$ & $-1.080 * *$ & -0.907 ** \\
\hline Number of persons in household & & 1.186 *** & 1.066 ** & 0.650 ** \\
\hline From single to marry & & $7.783 * \star \star$ & 6.956 *** & $4.825 * * *$ \\
\hline
\end{tabular}




\begin{tabular}{|c|c|c|c|c|}
\hline From couple to single & & 9.496 *** & $9.480 * \star \star$ & 2.473 \\
\hline Employed & & & $2.329 * \star$ & $2.547^{\star \star \star \star}$ \\
\hline Unemployed & & & $-2.641 *$ & -0.060 \\
\hline Receiver of a benefit & & & 1.511 & 1.428 \\
\hline Student & & & -2.539 & $-2.078 *$ \\
\hline Labour income Q1-Q2 & & & -0.210 & 0.284 \\
\hline Labour income Q2-Q3 & & & 0.243 & 0.401 \\
\hline Labour income $>Q 3$ & & & 0.814 & 1.068 * \\
\hline \%non-western in the origin neighbourh. & & & & $-0.300 * * \star$ \\
\hline Amsterdam & & & & $-11.729 *$ \\
\hline Rotterdam & & & & -8.324 \\
\hline The Hague & & & & -9.327 ** \\
\hline Constant & $50.274^{\star \star \star}$ & $46.278^{* \star \star}$ & 45.686 *** & 67.572 *** \\
\hline \multicolumn{5}{|c|}{ Selection equation (Dependent variable is the propensity to move) } \\
\hline Age 18-25 & $0.838 * \star \star$ & $0.836 * \star \star$ & $0.849 * \star \star$ & 0.844 *** \\
\hline Age 26-35 & $0.599 * * *$ & $0.593 * * \star$ & $0.581 * \star \star$ & $0.582 * \star *$ \\
\hline Age $36-45$ & $0.281 * \star \star$ & $0.274 * \star \star$ & $0.262 * \star \star$ & $0.263 * \star *$ \\
\hline Age $46-55$ & $0.089 * \star$ & 0.087 ** & $0.078 * \star$ & $0.077^{\star *}$ \\
\hline Woman & -0.006 & -0.007 & 0.002 & 0.007 \\
\hline Moroccan & -0.138 ** & $-0.127 *$ & $-0.111 *$ & 0.036 \\
\hline Turkish & $-0.148 *$ & $-0.142 *$ & -0.130 * & 0.012 \\
\hline Surinamese & $-0.181 * \star \star$ & $-0.170 * *$ & $-0.162 * \star$ & 0.008 \\
\hline Antillean & -0.023 & -0.008 & 0.009 & 0.117 \\
\hline Other Non-western & 0.056 & 0.070 * & 0.084 ** & $0.175 * \star *$ \\
\hline Western & -0.021 & -0.013 & -0.008 & 0.032 \\
\hline Second generation & -0.011 & -0.014 & -0.017 & -0.041 \\
\hline Homeowner & $-0.116 * \star *$ & $-0.072^{* \star}$ & $-0.078 * \star$ & 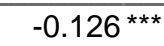 \\
\hline Log value of home in 1000 s & -0.200 *** & $-0.212^{\star \star \star}$ & $-0.210 * * \star$ & $-0.195^{\star \star \star}$ \\
\hline Married & $-0.223 * \star \star$ & $-0.226 * \star \star$ & $-0.232 * \star \star$ & -0.246 *** \\
\hline Number of children in household & -0.008 & $-0.029 *$ & -0.024 & -0.020 \\
\hline Number of persons in household & -0.015 & 0.007 & 0.004 & -0.006 \\
\hline From single to marry & $0.210 * \star \star$ & $0.348 * \star \star$ & $0.337 * * *$ & $0.336 * * *$ \\
\hline From couple to single & $0.875^{\star \star \star}$ & $1.062^{\star \star \star}$ & 1.066 *** & $1.081^{\star \star \star}$ \\
\hline Employed & -0.007 & -0.008 & 0.027 & 0.039 \\
\hline Unemployed & -0.065 & -0.062 & -0.101 ** & $-0.071 *$ \\
\hline Receiver of a benefit & -0.044 & -0.043 & -0.021 & -0.022 \\
\hline Student & 0.064 & 0.065 & 0.013 & 0.021 \\
\hline Labour income Q2 & $-0.052 *$ & $-0.050 *$ & $-0.052 *$ & $-0.050 *$ \\
\hline Labour income Q3 & -0.021 & -0.020 & -0.014 & -0.009 \\
\hline Labour income Q4 & -0.022 & -0.021 & -0.008 & 0.001 \\
\hline Log mean value of houses in neigh & -0.023 & -0.018 & -0.020 & -0.026 \\
\hline$\%$ owner occupied houses in neigh. & 0.000 & 0.000 & 0.000 & 0.000 \\
\hline Unemployment rate in neigbourhood & 0.014 ** & 0.014 ** & 0.014 ** & $0.015^{* * *}$ \\
\hline Log mean labour income in neigh. & $0.398 * * *$ & $0.407 * \star \star$ & $0.406 * \star \star$ & $0.353 * * *$ \\
\hline$\%$ non-western in the origin neigh. & $-0.049 *$ & $-0.049 *$ & -0.048 * & $-0.046 *$ \\
\hline Both parents in the same municipality & -0.081 ** & $-0.080 * \star$ & $-0.080 * \star$ & -0.086 ** \\
\hline One parent in the same municipality & 0.009 & 0.007 & 0.007 & 0.014 \\
\hline No parent in the same municipality & $0.006 * \star \star$ & $0.006 * \star \star$ & $0.006 * * *$ & 0.001 \\
\hline Amsterdam & 0.024 & 0.029 & 0.027 & -0.148 \\
\hline Rotterdam & -0.001 & 0.004 & 0.002 & -0.137 \\
\hline The Hague & 0.176 & 0.177 & 0.175 & 0.041 \\
\hline Constant & -1.839 *ᄎ* & $-1.894^{\star \star \star}$ & $-1.912^{\text {*** }}$ & $-1.705^{\text {*** }}$ \\
\hline rho & 0.744 *** & $0.753 * \star \star$ & $0.747 * * \star$ & $0.470 * \star *$ \\
\hline lambda & $14.744^{\star \star \star}$ & $14.938 * \star \star$ & 14.626 *** & $6.755^{\star \star \star *}$ \\
\hline $\mathrm{N}$ & 92141 & 92141 & 92141 & 92141 \\
\hline
\end{tabular}


$\mathrm{N}-$ Censored

83475

83475

83475

83475

$* \mathrm{p}<.05 ; * * \mathrm{p}<.01 ; * * * \mathrm{p}<.001$.

Standard errors are clustered on the municipality level

\subsection{Decomposing differential}

The estimates of linear models show that the types of destination neighbourhoods differ substantially between native and immigrant groups. Significant differences in the age distribution, household, and socioeconomic characteristics of natives and immigrant groups explain some part of ethnic mobility differentials, but much of the differentials remains unexplained by the factors observed. In order to uncover the explained and unexplained parts of mobility differences between natives and separate ethnic groups, we adopted the Oaxaca-Blinder linear decomposition technique (Oaxaca, 1973; Blinder, 1973) using the separate regression models for each group. We clustered the migrants into two groups: western and non-western. This technique is widely used in the economics literature to decompose wage and employment differentials between various ethnic groups or between men and women into two components: differentials attributed to differences in endowments or observed characteristics, and an unexplained component, which may be supposed to capture labour market discrimination (Oaxaca,1973; Blinder, 1973; Catton, 1988; Neumark, 1988, Oaxaca \& Ransom, 1994; Neuman \& Oaxaca, 2004).

In this study, we applied this decomposition technique to assess the native-immigrant differentials in destination-neighbourhood types that cannot be explained by the characteristics of the ethnic groups in the models. This unexplained part may be attributed to two main groups of factors. First, the majority population can hinder the spatial assimilation of ethnic minority groups. For instance, discrimination in the housing market, both for renters and buyers, and other institutional factors can hamper the mobility of ethnic minority groups towards places with a higher share of natives. Second, ethnic minority groups' own preferences may be a reason for remaining in an immigrant neighbourhood. These two components of unexplained differentials are hard to distinguish in the administrative data without additional information about attitudes. However, this unexplained part of the choice behaviour might reflect the preferences of natives and ethnic minorities to live in neighbourhoods with a higher share of their own ethnic group, and discrimination. The absence of sound empirical evidence on discrimination hints at the difficulty of assessing discrimination in the housing market, since in the Netherlands discrimination is likely to be subtle. This contention also supports our implicit strategy to assess the unexplained component of mobility. After controlling for relevant demographic and socioeconomic characteristics, residing closer to co-ethnics may indicate migrants' preferences shaped by comparative advantages of ethnic good and networks. 
According to the Oaxaca-Blinder technique, the observed mean differential of the percentage of natives in the destination neighbourhood, $\bar{P}_{n}-\bar{P}_{m}$, is decomposed into two components by the following equation ${ }^{2}$ :

$$
\bar{P}_{n}-\bar{P}_{m}=\hat{\beta}_{n}\left(\bar{X}_{n}-\bar{X}_{m}\right)+\bar{X}_{m}\left(\hat{\beta}_{n}-\hat{\beta}_{m}\right)
$$

where the subscripts $n$ and $m$ denote natives and immigrant groups, clustered into two groups as Surinamese/Antilleans and Turks/Moroccans in view of the similarities between the groups. $\bar{X}_{n}$ and $\bar{X}_{m}$ are the mean values for the regressors; $\hat{\beta}_{n}$ and $\hat{\beta}_{m}$ are the associated coefficients. The first term on the right hand side, $\hat{\beta}_{n}\left(\bar{X}_{n}-\bar{X}_{m}\right)$, is a differential owing to the characteristics and the second term $\bar{X}_{m}\left(\beta^{*}-\hat{\beta}_{m}\right)$ gives unexplained differentials.

In the original form of the decomposition, Oaxaca (1973) proposes either a male or female wage structure as the non-discriminatory wage structure. Later studies suggest a non-discriminatory wage structure $\beta^{*}$ be estimated, so that (6) becomes

$$
\bar{P}_{n}-\bar{P}_{m}=\hat{\beta}_{n}\left(\bar{X}_{n}-\bar{X}_{m}\right)+\left\lfloor\bar{X}_{n}\left(\hat{\beta}_{n}-\beta^{*}\right)+\bar{X}_{m}\left(\beta^{*}-\hat{\beta}_{m}\right)\right\rfloor
$$

where the estimated non-discriminatory structure is given as

$$
\beta^{*}=\Omega \hat{\beta}_{n}+(I-\Omega) \hat{\beta}_{m}
$$

Catton [5] suggests a weighting matrix $(\Omega)$ reflecting the share of the majority group in the sample $\left(I_{n}\right), \Omega=I_{n} I$. Neumark (1988) proposes a least-squares criterion to estimate a weighting matrix from the pooled sample of all the groups distinguished, $\beta^{*}=\left(X^{\prime} X\right)^{-1}\left(X^{\prime} P\right)=\hat{\beta}$, where $X$ is the observation matrix, $P$ is the observation vector of the response variable and $\hat{\beta}$ is the OLS estimate obtained from the pooled sample.

Neumark (1988) and Oaxaca \& Ransom (1994) show that the extent of the unexplained part is sensitive to the choice of a non-discriminatory structure. In our case, the unexplained part of location-choice differentials would cover preferences as indicated. Hence, an indifferent preference structure may be equivalent to a non-discriminatory wage structure. There is, however no unambiguous criterion to define an indifferent-preference structure. We therefore calculated alternative decompositions using three weighting matrixes: in the first and second cases, an indifferent-preference structure is assumed to be equal to the preference structure of natives and immigrant groups respectively. In other words, the location choice of the majority group (natives) or immigrant groups prevails. Alternatively, as Neumark suggests (1988), a common-preference structure derived from the pooled sample of natives and migrants is assumed to represent an indifferent-preference structure. This approach implies that natives and ethnic minorities

\footnotetext{
2 This decomposition formula does not include a separate selection component, since we have estimated MLE selection models rather than Heckman two-step models. In this case, any possible selectivity effect has already been captured by the estimated coefficients.
} 
contribute to an indifferent-preference structure according to their weighted share in the entire population.

\subsection{Results}

To decompose ethnic differentials in the destination-neighbourhood types according to the share of natives, we first estimated selection models with identical variables for natives, western, and non-western migrants using the MLE estimator with selectivity correction. The Parameter estimates for both models are displayed in Table A1 in the appendix. A likelihood-ratio test indicates that the null hypothesis of a zero correlation between the residuals of location choice equation and the selection equation $(\rho=0)$ can be rejected for the selection models for natives and western migrants, with $\chi^{2}=39.61$ for natives and $\chi^{2}=7.75$ for western migrants. The independence of the two equations cannot, however, be rejected for non-western migrants, with $\chi^{2}=0.66$. This result suggests that the MLE estimation of the selection model provides consistent, asymptotically efficient estimates for all the parameters in the models for natives and western migrants, but for non-western migrants OLS provides unbiased parameter estimates. We therefore estimated the location-choice equation using the OLS estimator not only for nonwestern migrants, but also for natives and western migrants, to show the consequences of ignoring selectivity. The sign of the selection coefficient lambda for natives and migrants is interesting. As expected, it is positive and statistically significant for natives and western migrants, which indicates the positive selectivity of native movers: those who tend to move to neighbourhoods with a large proportion of natives have a higher probability of moving. This result confirms the particular role of the mobility of the dominant group in the sorting process (Clark, 1991). The lambda coefficient is not statistically significant for non-western migrants.

Using MLE and OLS estimates, we calculated alternative decompositions for the differentials between native and non-western migrants, and between native and western migrants, based on the same type estimator. Subsequently, relying on the above information about the consistent and efficient estimates for natives and non-western migrants, we calculated the decompositions for these groups using the MLE estimates for natives and the OLS estimates for non-western migrants. Hence, the discrepancy between the results from this last estimation and the results obtained from the OLS or MLE estimates with selectivity correction will implicitly reflect the differential resulting from the selection of native movers. The results of the decomposition analyses are presented in table 5. As mentioned above, three weighting matrixes are used to calculate explained and unexplained parts of the differentials in the native share of the destination neighbourhood. The first column in table 5 refers to the weighting matrix applied. The first and second decompositions are obtained from the weighting matrix assuming that the majority and migrants respectively are the reference. The third decomposition uses the pooled sample as the reference. 
Table 5. Decomposition of native-immigrant differentials in the concentration of natives in the destination neighbourhood of movers

\begin{tabular}{|c|c|c|c|c|c|c|c|c|c|c|c|}
\hline \multirow[b]{3}{*}{ Reference } & \multirow[b]{3}{*}{ Decomposition } & \multicolumn{6}{|c|}{ Native - non-western } & \multicolumn{4}{|c|}{ Native - western } \\
\hline & & \multicolumn{2}{|l|}{ OLS } & \multicolumn{2}{|l|}{ MLE } & \multicolumn{2}{|l|}{ MIXED } & \multicolumn{2}{|l|}{ OLS } & \multicolumn{2}{|l|}{ MLE } \\
\hline & & Diff. & S.E. & Diff. & S.E. & Diff. & S.E. & Diff. & S.E. & Diff. & S.E. \\
\hline \multirow{3}{*}{ Native } & Explained & 8.91 & 2.24 & 8.35 & 2.30 & 7.90 & 2.22 & 2.06 & 1.19 & 2.07 & 1.24 \\
\hline & By \%n-west & 5.67 & 1.11 & 5.36 & 1.09 & 5.13 & 1.06 & 1.13 & 0.47 & 1.03 & 0.45 \\
\hline & Unexplained & 9.73 & 2.14 & 8.41 & 10.74 & 0.07 & 3.52 & 4.23 & 1.66 & 3.28 & 5.50 \\
\hline \multirow{3}{*}{ Immigrant } & Explained & 9.84 & 2.38 & 10.13 & 2.51 & 9.62 & 2.39 & 2.35 & 1.20 & 2.37 & 1.31 \\
\hline & By \%n-west & 5.40 & 0.98 & 5.84 & 1.07 & 5.31 & 0.99 & 0.99 & 0.43 & 0.95 & 0.44 \\
\hline & Unexplained & 8.81 & 1.78 & 6.63 & 10.81 & -1.66 & 3.16 & 3.93 & 1.61 & 2.99 & 5.40 \\
\hline \multirow{3}{*}{ Pooled } & Explained & 11.62 & 2.46 & 10.95 & 3.70 & 8.27 & 2.28 & 2.22 & 1.19 & 2.21 & 1.23 \\
\hline & By \%n-west & 7.04 & 1.29 & 6.87 & 2.14 & 5.24 & 1.16 & 1.13 & 0.47 & 1.04 & 0.46 \\
\hline & Unexplained & 7.03 & 1.50 & 5.82 & 7.87 & -0.31 & 2.50 & 4.06 & 1.61 & 3.14 & 5.35 \\
\hline \multicolumn{2}{|c|}{ Predicted Difference } & 18.65 & 2.92 & 16.77 & 10.87 & 7.96 & 3.91 & 6.28 & 1.98 & 5.36 & 5.58 \\
\hline
\end{tabular}

The figures in bold are significant at the .05 level

Consider first the estimated differentials between natives and non-western migrants. The predicted mean differentials obtained from OLS and the selection models are fairly small: 18.65 and 16.77 points respectively. These predictions are very close to the observed differential as shown in table 1. The distribution of the differential across explained and unexplained parts varies slightly across the type of weighting matrix applied. The contribution of observed characteristics rises slightly when the immigrant group is taken as the reference, whereas the unexplained part is relatively higher when natives are the reference. Since an indifferentpreference structure is derived from the pooled sample, the proportion of the explained part is even greater than these two extreme cases. In this case, 62 to 65 percent of native-immigrant mobility differences (about 11 percentage points) is explained by observed characteristics. The remaining 35 percent is likely to be upper bound for the difference owing to preferences. This last approach that relies on the composition of current society as whole rather than taking natives or migrants as reference, probably gives a more realistic picture. This result is similar to the outcome for Asians (53 percent) in the study of Bayer and colleagues (2004), who used a different strategy from that applied in this study. They could explain 92.5 percent of the segregation for Hispanics and approximately 30 percent for Whites and Blacks.

The results obtained from OLS and selectivity-corrected MLE estimators are small, as mentioned above. However, the distribution of the differential across 'explained' and 'unexplained' is much more pronounced when the decompositions are based on the selectivity-corrected MLE model for natives and OLS estimator for non-western migrants, according to the criteria of unbiased parameter estimates as discussed above. This last method provides a lower differential than the other estimates do: 7.96 versus 18.65 and 16.77 percentage points. The entire differential is derived from observed characteristics when the indifferent-preference structure is supposed to be derived from the pooled sample. Comparing this result with the decomposition based on the OLS estimator may suggest that a decomposition-based OLS estimator overestimates the nativeimmigrant difference by about 10 percentage points and the relative share of unexplained differential when the selectivity bias of native movers is not considered. These results also imply that ethnic residential segregation is mainly derived from the selective mobility behaviour of natives. Movers among non-western migrants are not self-selected considering the ethnic composition of neighbourhoods, neither positively nor negatively. 
Among the variables used in the models, the segregation indicator for the origin neighbourhood approximated by the concentration of non-western migrants is of particular importance. The estimated coefficient for this variable is negative and statistically significant for the models of natives and migrants. The segregation indicator variable contributes substantially to the nativenon-western differential explained by the characteristics: about 5 to 7 points (more than half the explained total). This implies that the residents of more segregated neighbourhoods are less likely to choose neighbourhoods with a higher share of natives. Since a relatively greater share of migrants reside in neighbourhoods with a heavy concentration of non-western migrants, the impact of the segregation variable becomes dominant in the decomposition results for nonwestern migrants.

The difference in the mobility patterns of natives and western migrants is less pronounced: about 6 percentage points, when the decomposition is based on the OLS estimates. Two thirds of this difference cannot be explained by observed characteristics. The difference is more than 5 percent when the selectivity-corrected MLE model is stressed. Again, two thirds of this differential is unexplained. It is worthy of note that this difference is estimated less precisely. This implies that the difference between natives and western migrants cannot be explained from different characteristics of these groups, but probably to a large extent from preferences.

\subsection{Differences across distances and generations}

Since migrants are concentrated in some neighbourhoods of large cities and a large part of the mobility is short-distance oriented, one may expect the probability for migrants to move to another immigrant neighbourhood to be relatively large. Moreover, the short-distance mobility is driven by considerations to improve housing quality, while long-distance mobility is often brought about by labour market events. Non-western migrants are usually relatively low skilled, and less well-educated people would be less likely to move to another place because of a new job. This tendency may colour our results. To test the consistency of our results with respect to distance, we calculated our estimates separately for short- and long-distance mobility dichotomizing the mobility into within and between municipalities. Table 6 displays the decomposition results for short- and long-distance movers, based on the OLS estimates ${ }^{3}$. It is immediately apparent that the differences in the mobility patterns of natives and non-western migrants are larger for short-distance mobility than for long-distance mobility (20 versus 14 percentage points). A substantial part of this difference - that is, 16 of the 20 percentage points can be explained by different characteristics, while a relatively smaller part of the difference in the long-distance mobility is explained by observed characteristics - that is, 4 of the 14 percentage points. This result confirms our intuition that migrants who intend to mix with natives tend to move to neighbourhoods at a relatively longer distance away.

\footnotetext{
3 The underlying parameter estimates are not presented here, but are available on request.
} 
Table 6. Decomposition of native-immigrant differentials in the destination-neighbourhood types, based on OLS estimates

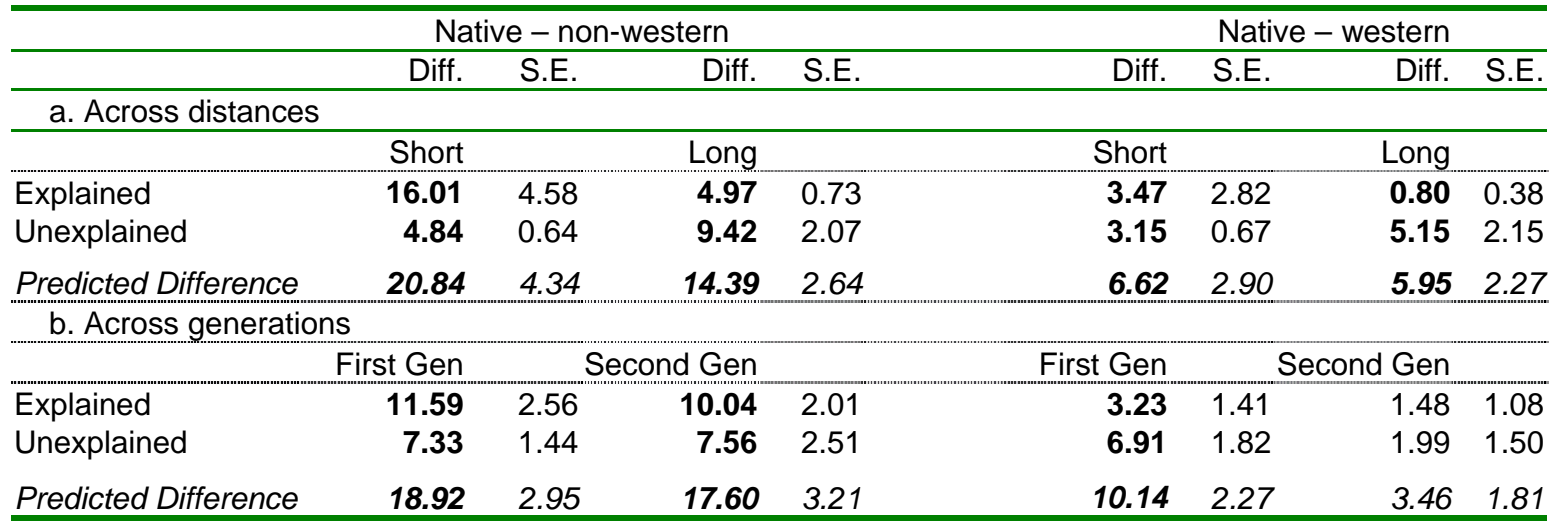

The figures in bold is significant at the .05 level.

Up to this point, the study has not distinguished between first- and second-generation migrants. According to the spatial assimilation theory, which predicts closer geographical proximity between the second generation and natives compared with the first generation, these two groups could differ in their mobility behaviour (South et al., 2005; Massey and Denton, 1985). We therefore conducted separate analyses for the first- and second-generation migrants; they are reported in table 5. The results are fairly similar for the first and second generations of nonwestern migrants in terms of both the size and the composition of the difference. This implies that there is no indication of spatial assimilation of the second-generation non-western migrants. On the other hand, the mobility pattern of the second generation of western migrants does not differ significantly from that of natives if the share of natives in the destination neighbourhood is 10 percentage points lower. This figure suggests the full assimilation of the second generation of western migrants, in contrast with their parents.

\section{Conclusions}

We have examined the spatial-mobility patterns of natives and migrants using rich individual administrative data. The observed spatial mobility among non-western migrants is almost twice the mobility rate of natives; the probabilities of moving are 14 versus 7.7 percent. The propensity to move is relatively high among natives who reside in neighbourhoods with a higher share of non-western migrants. The estimates indicate a segregatory tendency among non-western migrants and natives. The native movers tend to choose neighbourhoods with a higher share of natives, while non-western migrants are less likely to choose native neighbourhoods.

The study shows that the native movers and immigrant movers from western countries are positively selected: those who are more likely to move to neighbourhoods with a larger share of natives have a higher probability of moving in any case. The mobility of non-western migrants seems not to be selective. The decomposition analysis predicted a difference of around 17 to 18 percentage points in the percentage of natives in the destination neighbourhood between native and non-western movers. About 65 percent of this differential can be explained by nativeimmigrant differences in observed characteristics and the rest is unexplained. This unexplained component may largely be derived from preferences, discrimination, and some unobserved 
ethnic-specific restrictions in the housing market. It is evident that the maximum of preferences may be around 35 percent. The exact share of preferences and discrimination is, however, hard to document. It has been shown that the origin neighbourhood is influential in determining the native concentration in the destination neighbourhood. The inhabitants of neighbourhoods with a higher share of non-western migrants are less likely to move to areas where the concentration of natives is high.

The analysis shows that migrants tend to mix with natives relatively more when they move to other municipalities (long-distance move) rather than remain within the same municipality (shortdistance moves). In addition, the role of preferences is relatively large for the long-distance movers. Considering the spatial assimilation of migrants in terms of geographical proximity with natives, the mobility pattern of the first and second generation is fairly similar for non-western migrants. This similarity suggests that there is no evidence of the spatial assimilation of nonwestern migrants across the generations. On the contrary, the mobility behaviour of the secondgeneration western migrants is similar to that of natives, while the first generation tends to move to neighbourhoods where the share of natives is some percentage points lower. That result means that the second generation of western migrants bridges the gap between their parents and the majority population. 


\section{Appendix}

Table A.1. Regression estimates

\begin{tabular}{|c|c|c|c|c|c|c|c|}
\hline & \multicolumn{3}{|c|}{ MLE with selection } & \multicolumn{4}{|c|}{ OLS } \\
\hline & Native & Non-west & West & & Native & N-west & West \\
\hline \multicolumn{8}{|c|}{ Dependent variable is percentage of natives in the destination neighbourhood } \\
\hline Age $18-25$ & $2.837 * \star$ & 4.707 & 0.619 & & $-1.725 *$ & 0.767 & -1.680 \\
\hline Age $26-35$ & $2.237 *$ & 6.007 & -0.407 & & -0.925 & 2.957 & -2.069 \\
\hline Age $36-45$ & 0.672 & 2.609 & -2.080 & & -0.748 & 1.456 & -2.456 \\
\hline Age $46-55$ & -0.620 & 2.827 & -3.877 & & -1.371 & 2.716 & -3.262 \\
\hline Woman & 0.856 * & 1.150 & 1.366 & & 0.825 * & 1.067 & 0.944 \\
\hline Homeowner & 0.191 & 2.019 & 1.802 & & $0.918 * \star$ & 1.730 & $2.430 * \star$ \\
\hline Married & 1.285 ** & 0.528 & -0.569 & & $2.780 * \star \star$ & 1.527 & 0.891 \\
\hline Number of children in household & -0.806 * & -1.305 & 0.325 & & -0.600 & -0.619 & -0.828 \\
\hline Number of persons in household & $0.634^{* *}$ & 0.878 & -0.630 & & 0.496 * & 0.772 & 0.426 \\
\hline From single to marry & $4.888 * \star \star$ & 5.113 & 3.415 & & $3.348 * * *$ & 4.238 & 1.739 \\
\hline From couple to single & 2.796 & 1.116 & -2.333 & & $-3.163 * \star \star$ & -1.640 & -6.100 \\
\hline Employed & 0.960 & 4.697 ** & $8.901 * * *$ & & 0.911 & $4.941 * \star$ & $7.019 * * *$ \\
\hline Unemployed & -2.433 * & 2.543 & 6.906 * & & -2.220 * & 2.994 & 5.354 \\
\hline Receiver of a benefit & -0.461 & 3.684 & $9.529 * \star *$ & & -0.941 & 4.536 & 8.058 ** \\
\hline Student & $-3.819 * \star \star$ & 1.425 & 1.671 & & $-4.230 * \star \star$ & 3.029 & -0.473 \\
\hline Labour income Q1-Q2 & 0.396 & -0.015 & -0.636 & & 0.358 & 0.897 & -0.055 \\
\hline Labour income Q2-Q3 & 0.418 & -0.658 & 0.642 & & 0.471 & -0.136 & 1.440 \\
\hline Labour income $>\mathrm{Q} 3$ & 0.544 & 2.686 & $3.819 * *$ & & 0.303 & 2.642 & 3.284 ** \\
\hline$\%$ non-western in the origin neighbourh. & $-0.291 * * *$ & $-0.317 * \star \star$ & -0.266 *** & & $-0.316 * \star \star$ & $-0.301 * \star \star$ & $-0.281 * \star \star$ \\
\hline Amsterdam & $-12.065^{*}$ & $-11.175^{*}$ & $-14.246 *$ & & $-11.644 *$ & $-11.723 *$ & $-12.507 * *$ \\
\hline Rotterdam & -7.354 & $-9.961 * \star$ & $-10.570 *$ & & -7.448 & $-10.258 * *$ & $-9.655 *$ \\
\hline The Hague & $-8.812 *$ & $-11.923 * \star *$ & -7.942 & & $-9.486 * \star \star$ & 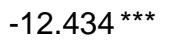 & -7.309 \\
\hline Constant & $69.602^{* * *}$ & 55.768 *** & 62.752 *** & & $82.994 * \star \star$ & $65.397 * \star *$ & 73.036 *** \\
\hline \multicolumn{8}{|c|}{ Selection model (Dependent variable is the propensity to move) } \\
\hline Age 18-25 & $0.876 * \star \star$ & $0.739 * \star \star$ & 0.652 *** & R2 & 0.256 & 0.303 & 0.238 \\
\hline Age 26-35 & $0.599 * * \star$ & $0.514 * \star \star$ & $0.520 * * *$ & $\mathrm{~N}$ & 7167 & 1397 & 947 \\
\hline Age $36-45$ & $0.263 * * \star$ & 0.238 ** & 0.242 ** & & & & \\
\hline Age $46-55$ & 0.093 ** & -0.008 & 0.021 & & & & \\
\hline Woman & 0.019 & -0.041 & 0.019 & & & & \\
\hline Homeowner & $-0.120 * \star \star$ & $-0.133 * \star$ & $-0.132 *$ & & & & \\
\hline Married & $-0.248 * \star *$ & $-0.237 * * *$ & $-0.225 * * *$ & & & & \\
\hline Number of children in household & -0.018 & -0.057 & 0.063 & & & & \\
\hline Number of persons in household & 0.005 & -0.015 & -0.074 & & & & \\
\hline From single to marry & $0.365 * * \star$ & 0.257 * & 0.155 & & & & \\
\hline From couple to single & $1.183^{* * \star}$ & $0.606 * \star *$ & $0.887 * \star *$ & & & & \\
\hline Employed & 0.042 & -0.049 & 0.181 * & & & & \\
\hline Unemployed & -0.062 & $-0.170 *$ & 0.077 & & & & \\
\hline Receiver of a benefit & 0.018 & $-0.325 * \star$ & 0.071 & & & & \\
\hline Student & 0.035 & $-0.222 *$ & $0.349 * *$ & & & & \\
\hline Labour income Q1-Q2 & -0.024 & $-0.171 * \star$ & -0.052 & & & & \\
\hline Labour income Q2-Q3 & 0.009 & -0.049 & -0.046 & & & & \\
\hline Labour income $>\mathrm{Q} 3$ & 0.023 & -0.075 & 0.010 & & & & \\
\hline Log value of home in 1000s & $-0.203 * \star *$ & -0.215 & $-0.139 *$ & & & & \\
\hline Log mean value of houses in neighb. & -0.022 & 0.149 & -0.069 & & & & \\
\hline$\%$ owner occupied houses in neighb. & 0.000 & 0.001 & -0.001 & & & & \\
\hline Unemployment rate in neighbourhood & 0.021 *** & -0.006 & 0.016 & & & & \\
\hline Mean labour income in neighbour. & $0.443 * \star *$ & -0.158 & 0.202 & & & & \\
\hline$\%$ non-western in the origin neighb. & 0.002 & 0.001 & -0.001 & & & & \\
\hline both parents in the same municipality & -0.053 * & -0.045 & -0.086 & & & & \\
\hline
\end{tabular}




\begin{tabular}{lcrr}
\hline One parent in the same municipality & $-0.099^{* *}$ & -0.012 & -0.100 \\
No parent in the same municipality & 0.012 & -0.102 & 0.016 \\
Amsterdam & -0.179 & 0.013 & -0.334 \\
Rotterdam & -0.122 & -0.042 & -0.211 \\
The Hague & 0.083 & -0.006 & 0.079 \\
Constant & $-2.075^{\star * *}$ & -0.394 & -1.132 \\
& & & \\
rho & 0.491 & 0.316 & 0.395 \\
lambda & 13.130 & 18.130 & 15.011 \\
$\mathrm{~N}$ & 74511 & 8971 & 8659 \\
$\mathrm{~N}$-Censored & 68008 & 7671 & 7796 \\
\hline
\end{tabular}

$* \mathrm{p}<.05 ; * * \mathrm{p}<.01 ; * * * \mathrm{p}<.001$.

Standard errors are clustered on the municipality level

\section{References}

Bayer, P., R. McMillan and K.S. Rueben (2004). What drives racial segregation? New evidence using census microdata, Journal of Urban Economics 56, 514-535

Blinder, A. S. (1973). Wage discrimination: Reduced form and structural estimates, Journal of Human Resources 8, 436-455.

Bolt, G. and R. van Kempen (2003). Escaping poverty neighbourhoods in the Netherlands, Housing, Theory and Society 20, 209-222.

Bontje, M. and J. Latten (2005). Stable size, changing composition: recent migration dynamics of the Dutch large cities, Tijdschrift voor Economische en Sociale Geografie, 96, 444-451.

Cotton, J. (1988). On the decomposition of wage differentials, Review of Economics and Statistics 70, 236-243.

Clark,W. A. V. (1991). Residential preferences and neighborhood racial segregation: A test of the Schelling segregation model, Demography 28, 1-19.

Clark, W. A. V. (1992).Residential preferences and residential choices in a multiethnic context, Demography 29, 451-466.

Crowder, K. (2000). The racial context of white mobility: An individual-level assessment of the white flight hypothesis, Social Science Research 29, 223-257.

Crowder, K., S.J. South and E. Chavez (2006). Wealth, race and inter-neighborhood migration, American Sociological Review 71, 72-94.

Cutler, D., M., E. L. Glaeser and J. L. Vigdor (1999). The rise and decline of the American ghetto, Journal of Political Economy 107, 455-506.

Dawkins, C. J. (2006). Are social networks the ties that bind families to neighborhoods? Housing Studies 21, 867-881. 
Farley, R., H. Schuman, S. Bianchi, D. Colasanto, S. Hatchett (1978). Chocolate city, vanilla suburbs: will the trend toward racially separate communities continue? Social Science Research 7, 319-344.

Farley, R., C.G. Steeh, M. Krysan, K. Reeves, T. Jackson (1994). Stereotypes and segregation: neighbourhoods in Detroit area, American Journal of Sociology 100, 750-778.

Galster, G. C. (1990). White flight from racially integrated neighbourhoods in the 1970s: the Cleveland experience, Urban Studies 27, 385-399.

Heckman, J. J. (1979). Sample selection bias as a specification error, Econometrica 47, 153-162.

Krysan, M. (2002). Whites who say they'd flee: who are they and why would they leave? Demography 39, 675-696

Latten, J., H. Nicolaas and K. Wittebrood (2005). Concentratie allochtonen toegenomen, Bevolkingstrends 3, 90-95

Massey, D.S. and N.A. Denton (1985). Spatial assimilation as a socioeconomic outcome. American Sociological Review 50, 94-106

Musterd, S. (2005). Social and ethnic segregation in Europe: Levels, causes, and effects, Journal of Urban Affairs 27, 331-348.

Musterd, S., W. Ostendorf and S. de Vos (2003). Neighbourhood effects and social mobility: A longitudinal analysis, Housing Studies 18, 877-892.

Musterd, S. and S. de Vos (2007). Residential dynamics in ethnic concentration, Housing Studies 22, 333-353.

Nawata, K. and N. Nagase (1996). Estimation of sample selection bias models, Econometric Reviews 14, 387-400

Neumark, D. (1988). Employers' discriminatory behavior and the estimation of wage discrimination, Journal of Human Resources 23, 279-295.

Neuman, S. and R. L. Oaxaca (2004). Wage decompositions with selectivity-corrected wage equations: A methodological note, Journal of Economic Inequality 2, 3-10.

Oaxaca,R. (1973). Male-female wage differentials in urban labor markets, International Economic Review 14, 693-709.

Oaxaca, R. L. and M. R. Ransom (1994). On discrimination and the decomposition of wage differentials, Journal of Econometrics 61, 5-21.

Quillian, L. (2002). Why is black-white residential segregation so persistent?: Evidence on three theories from migration data, Social Science Research 31, 197-229.

Sartori, A.E. (2003). An Estimator for some binary outcome selection models without exclusion restrictions, Political Analysis 11, 11-138

Schelling, T. C. (1971). Dynamic models of segregation, Journal of Mathematical Sociology 1, 143-186.

South, S.J., K. Crowder and E. Chavez (2005). Migration and Spatial assimilation among U.S. Latinos: classical versus segmented trajectories. Demography 42, 497-521. 
Spilimbergo, A. and L. Ubeda (2004). Family attachment and the decision to move by race, Journal of Urban Economics 55, 478-497.

Wooldridge, J. (2002). Econometric Analysis of Cross Section and Panel Data, Cambridge: MIT Press

Zorlu, A. and C.M. Mulder (forthcoming), Initial and Subsequent Location Choices of Immigrants to the Netherlands. Regional Studies 